\title{
Reflexión sobre el desarrollo y sus implicaciones en el mundo contemporáneo
}

José Ramón Báez Osegueda ${ }^{1}$

Este ensayo se basa en una reflexión sobre la conferencia "El desarrollo y sus implicaciones en el mundo contemporáneo", realizada por la Dra. Tahina Ojeda Medina en el año $2015^{2}$ organizado por la Facultad de Ciencias Políticas y Sociología de la Universidad de Granada (UGR) de España en el marco del Ciclo de Conferencias: "Cooperación Internacional y Desarrollo: Reflexiones Críticas".

La Dra. Ojeda (2015) inicia su presentación afirmando que la reformulación del desarrollo implica empezar a plantearnos sobre lo que entendemos realmente por desarrollo. El ciudadano que está ligado a funciones académicas o laborales y trata con asuntos como: el desarrollo, la cooperación, proyectos de bienestar social y voluntariados; tiene la iniciativa o idea de querer hacer algo para que este mundo tal y como se encuentra concebido su funcionamiento, mejore y se transforme. Aunque parezca algo utópico tratar de cambiar el mundo contemporáneo, debe de existir necesariamente personas que lo hagan, ya que, si se les deja todo a los individuos que organizan y dirigen la política mundial vamos muy mal. Si se trabaja en cooperación internacional y en temas de desarrollo es esencial estudiar y prepararse mucho, puesto que hay unas grandes escuelas de pensamiento que nos han indicado desde el inicio de la idea del desarrollo y el subdesarrollo que el desarrollo es equiparable al crecimiento económico y que la economía es fundamental. Sin embargo, actualmente es más que eso, involucra los enfoques de capacidades y derechos, aunque el sustrato económico sigua siendo un enfoque importante, se trata de un aspecto mucho más amplio, que el común de la gente en todas las partes del mundo tengamos una vida digna.

Ojeda (2015) considera que en algún momento nos hemos planteado un concepto y construido una idea del desarrollo y en consecuencia hemos construido una idea del subdesarrollo equiparándolo con algo negativo o una situación no deseada que debe ser cambiada. Entonces, su reflexión gira en torno a: ¿Quién ha decidido que hay países y personas en el mundo que son subdesarrolladas?, esa es la primera pregunta que debemos hacernos, de dónde surgen estas ideas y por qué las hemos asumido como si fueran teorías infalibles, ¿Hasta el momento hemos consultado o nos han

Recibido: 08 de agosto de 2016

Aceptado: 20 de octubre de 2016

1 Estudiante de III año de Ciencias Políticas y Relaciones Internacionales. UNAN-Maangua/FAREM-Estelí. Correo Electrónico: baez033@gmail.com

2 La Dra. Tahina Ojeda Medina es investigadora y docente del Instituto Universitario de Desarrollo y Cooperación de la Universidad Complutense de Madrid. España. 
preguntado qué tipo de vida queremos tener?, al parecer no, quizá si nos hubiesen preguntado, la dirección del mundo en este momento fuera otra. De esta manera, se ha propuesto que el desarrollo es una situación deseable que se encuentra en un lugar y para llegar a el tenemos que hacer una serie de cosas que nos permita lograrlo, ese lugar era el espejo en el que nos habíamos reflejado intentando imitar aquellas condiciones que tenían los países que considerábamos desarrollados. Históricamente lo que ha ocurrido es que hemos tenido un solo modelo de desarrollo, el modelo capitalista, expandido a través de la cultura universal desde occidente a todo el planeta.

Es por ello, el primer concepto de desarrollo está relacionado al crecimiento económico y la cooperación internacional para el desarrollo se dirija directamente a los países subdesarrollados para permitir que pasen de naciones no desarrolladas a desarrolladas en materia de crecimiento económico. De ahí también las teorías económicas y sociológicas que planteaban que era necesario industrializarse y eliminar obstáculos institucionales, políticos, económicos y culturales para poder conseguir el desarrollo, (Ojeda, 2015).

Al determinarse que para que un país del sur pudiera llegar a la modernización e industrialización era necesario adaptarse a los cambios que el enfoque del desarrollo exige. Surgen, a partir, de los años 90 una serie de ideas de corte rupturistas que plantean que la era del desarrollo llegue a su fin y se proponga una alternativa diferente. Así, nace el enfoque de desarrollo humano y se empiezan a sumar una secesión de enfoques críticos, entre ellos: el post desarrollo, las teorías descoloniales, del descrecimiento y post coloniales. Justamente lo que plantean es la idea de que todo aquello que hemos pensado siempre que es el desarrollo, realmente es una forma de dominación, una manera de interferencia cultural, una construcción política que se ha ideado en un lugar geográfico y político del mundo que ha permeado y atravesado las culturas de todo el planeta. En función de esto se ha planteado que debemos tener un solo modelo de desarrollo, es decir, que no hay alternativas a desarrollar nada propio y lo único que se les presenta a los países del sur es destruir lo que posee porque se considera primitivo, tradicional y atrasado, para avanzar hacia ese camino. En consecuencia, este enfoque ha desestimado todas las raíces propias de los lugares del mundo, ya que, desde el enfoque del desarrollo las culturas de los pueblos son subdesarrollados, por tanto, implica que los desarrollados los apoyen para salir de la pobreza, pero que lo hagan a imagen y semejanza de estos. Es por esto que los enfoques críticos promueven la descolonización del pensamiento y del sistema económico y político de los países del sur para empezar a redescubrirse y plantear alternativas que generen otra forma de desarrollo. En conclusión la idea del desarrollo fue un mito, ha sido construido y difundido desde un lugar político y es una forma de dominación de los pueblos, a través, de la dominación se ha truncado el verdadero proceso de desarrollo cultural y económico de las naciones consideradas no desarrolladas (América Latina, países de África y algunas naciones del mundo en condiciones de pobreza), (Ojeda, 2015).

Al valorar las condiciones actuales de crecimiento en el mundo es relevante preguntarnos si después de setenta años de cooperación, está funcionando o no y qué alternativas tenemos. Plantearnos 
estas interrogantes nos ayuda a perfilar muchos más programas apegados a la realidad, es decir, escuchar a la gente y saber lo que realmente quieren para ser más eficaces. Los modelos actuales no son sostenibles, esto implica plantearnos un reto enorme, crear otros enfoques. Un caso está llamando la atención es la idea del buen vivir que Bolivia y Ecuador están aplicando actualmente en sus territorios y que de alguna manera están dando resultado principalmente porque procura rescatar las identidades de los grupos indígenas, en función de hacer cambios. Dentro de cada país una opción para empezar es que los países dejen de plantearse un modelo de desarrollo único y traten de crear agendas diversificadas, donde cada quien decida en comunidad que tipo de vida aspira, en función de eso, la cooperación internacional debe comenzar a trabajar no en agendas únicas sino en agendas diversificadas, esto significa que las instituciones internacionales tienen que cambiar su modos de operación y acción, (Ojeda, 2015).

El buen vivir, plantea que la forma que nos hemos trazado para crear desarrollo genera desigualdad, inequidad, pobreza y no permite la igualdad de oportunidades; pues no es desconocido que un porcentaje minoritario de la población tiene y despilfarra el ochenta por ciento de los recursos impidiendo la igualdad económica en el mundo, (Ojeda, 2015).

El contexto actual se basa en la agenda 20-30, Alianza Global para el Desarrollo, una agenda global para todo el planeta, se ha tomado lecciones aprendidas de los objetivos de desarrollo del milenio, pues de ocho objetivos se pasaron a diecisiete y ahora se involucra todo para eliminar todas las formas de pobreza, desde la formulación de la agenda inclusiva global. Aún se sigue trabajando con el paradigma del desarrollo humano sostenible, pero de fondo no se ha avanzado mucho. Dado este entorno, existe actualmente más actores del sur reivindicando su lugar en el mundo, pidiendo una distribución más equitativa del poder mundial porque los grandes temas y agendas que se plantean en el escenario internacional no son decididos de manera democrática, no se nos olvide que existe el derecho al veto de la institución mundial donde pertenecemos todos. También a nivel internacional los pueblos están cada vez más organizados y participativos intentando influir en las agendas de decisión para que los gobernantes planteen en los foros internacionales las demandas del pueblo, ya que, parte de esos planteamientos son nuestras formas de producción y consumo lo que hasta ahora, nos está llevando a la ruina, genera exclusión y desigualdad, (Ojeda, 2015).

Esta realidad nos compromete a pensar qué hacer para traducir ese sentimiento popular de la ciudadanía, ya que, las personas especializadas que dirigen y formulan los proyectos e instituciones de cooperación internacional se les olvida escuchar la calle, entonces, es necesario recuperar los saberes tradicionales, el sentido común que hay en la gente, puesto que, contribuiría en principio a crear y desarrollar agendas mucho más lógicas, (Ojeda, 2015).

En ese sentido, América Latina es la región donde más movimientos sociales se están organizando, también se ha generado una serie de cambios políticos desde el año dos mil que han favorecido a sectores que antes no habían sido escuchado, además, en el ámbito de la cooperación internacional 
el abanico de temas se ha ampliado y ahora se ve más oportunidades de trabajo en los sectores sociales. Aunque al final siempre los excluidos de las agendas de políticas públicas hayan sido los indígenas, las mujeres y los afrodescendientes. En América Latina, actualmente se están incluyendo muchos más temas y proyectos que rescaten estos aspectos tan importantes de la sociedad, gracias a la cooperación sur-sur; al observar estas iniciativas la cooperación internacional está empezando a tomar parte de las ideas que los países de sur están tratando, esto para procurar modernizar de alguna manera el sistema pero esa modernización realmente no significa una transformación del orden mundial, (Ojeda, 2015).

Al considerar los cambios no profundos que la cooperación internacional pueda hacer, muchos actores del sur opinan que tanto la cooperación sur-sur como la cooperación norte-sur deben estar separados, que sean alternativas de las cuales podamos elegir cual queremos o necesitamos. Al analizar el contexto internacional y las visiones críticas actuales nos damos cuenta que es posible replantear y cuestionar las ideas acerca del desarrollo y crear un despertar del gigante del sur, un despertar sobre todo político, de la ciudadanía y de los pueblos, (Ojeda, 2015).

\section{Reflexión crítica sobre la ponencia: el desarrollo y sus implicaciones en el mundo contemporáneo}

La reflexión de la doctora Ojeda lleva a retroceder en la historia y recordar los acontecimientos que provocaron la reconfiguración de la Sociedad Internacional. Primero, posterior a la Segunda Guerra Mundial se crean los organismos internacionales que se encargan actualmente de regir el funcionamiento de las relaciones políticas, económicas y sociales entre las naciones, segundo, se forman los bancos que controlan el intercambio y flujo financiero a escala mundial, en consecuencia, se establece, a partir, de estos momentos la formulación y creación de una agenda política capaz de dirigir el ejercicio de los actores políticos internacionales para generar de cualquier forma el crecimiento económico de aquellos países que se encontraban producto de las conquistas coloniales y de los efectos de las guerras en condiciones de pobreza o bajos niveles de industrialización.

Ahora bien, si efectivamente se creó la agenda global de desarrollo para los países del mundo, la pregunta es, ¿Quiénes fueron realmente los protagonistas que crearon las bases del funcionamiento del orden mundial?, sin duda alguna, los pueblos de América Latina o los en vías de desarrollo no tuvieron parte en este proceso, entonces, ¿Cómo es posible que aun así participen de la ejecución de la agenda global?, sencillamente por no ha existido otra alternativa que someterse a los dictados de los poderosos que controlaban las instituciones de poder político, económico y militar. Hoy parece que el panorama ha cambiado y afortunadamente los ciudadanos de los pueblos "subdesarrollados" tenemos al menos, la oportunidad de alzar nuestra voz en contra del sistema injusto e inequitativo que los directrices de la política mundial han configurado. 
Comúnmente se piensa que el término "desarrollo" significa una vida mejor para la gente o modernizarse, para otros es vivir como los ricos de la televisión; lo cierto es que este enfoque impulsado por el sistema internacional desde hace algunas décadas no ha sido lo suficiente sostenible para alcanzar el clima de avances que se les prometió a los países que se encuentran todavía en condiciones de pobreza. Esa idea utópica del desarrollo vendida por los países industrializados a los pueblos del sur no es más que el espejismo para seguir dominándolos e impedirles el verdadero despertar político que las naciones en vías de desarrollo han tratado de impulsar.

El "subdesarrollo" de unos, ha sido la condición para el "desarrollo" de los otros. A partir, de las conquistas, las riquezas de América Latina, África y Asia fueron transferidas a Europa donde sentaron las bases de la prosperidad. Gracias a la historia es posible entender por qué los países de estas regiones aún siguen siendo pobres, se comprende las atrocidades que los países "defensores de la humanidad" realizaron contra los habitantes del sur. Si en ese entonces, se hablaba de civilizarnos, las posturas actuales poco han variado, al parecer la independencia política de los territorios conquistados no significó el fin de la colonización, por el contrario, fue el inicio de la nueva misión civilizatoria: "desarrollar a los subdesarrollados".

Fue después de la Segunda Guerra Mundial que esta nueva lógica imperial de dominación se proclamó, se alzaba como las grandes esperanzas para la civilización, pero la realidad es que después de más de cinco décadas dedicadas al desarrollo, América Latina sigue siendo la región más desigual del planeta. Sin duda, nuestros países han mejorado y han logrado modernizarse en muchos aspectos, pero la desigualdad de oportunidades es uno de los problemas más alarmantes que actualmente afecta a la región.

Si el desarrollo consagra el modo de vida moderno, occidental, consumista y capitalista, entonces, definitivamente denigra otros estilos de vida, como los comunitarios e indígenas que desde el enfoque del desarrollo son considerados como atrasados y poco productivos. La idea del desarrollo no es más que una maquinaria controlada por los capitalistas para uniformar la cultura universal a sus designios, es el resultado la consagración de ciertos saberes y la marginación de otros. Con el proyecto hegemónico del desarrollo lo que si se logró fue hacernos perder la capacidad de autogestión.

El propósito principal de los países industrializados ha surtido efectos, ha impedido que los pueblos piensen por objetivos propios, ha socavado la confianza en uno mismo y el de nuestra cultura. Asimismo, ha debilitado tradiciones importantes como los trabajos comunitarios y la reciprocidad para convertirnos en receptores de dádivas y proyectos. Mientras el desarrollo promete modernización y enriquecimiento, para la gran mayoría ha significado siempre la modernización de la pobreza, es decir, los métodos aplicados para crear el desarrollo simplemente han sido estrategias superficiales para mantener la creciente dependencia económica y tecnológica de los pueblos del sur en la agenda y la guía de otros (Países Industrializados). En ese sentido, 
es relevante resaltar las ideas de la doctora Ojeda quien propone crear las bases de un desarrollo desde la creación y ejecución de agendas diversificadas, posiblemente sea esta una alternativa para detener los estragos provocados por el enfoque tradicional vigente. El desarrollo no es más que un espejismo, un neocolonialismo disfrazado.

Y qué podemos hacer para replantear esa realidad, probablemente lo primero es cuestionar el concepto de "desarrollo" que hemos naturalizado como algo positivo, evaluar colectivamente las experiencias de desarrollo que conocemos, los proyectos de nuestro entorno ¿Han funcionado?, ¿Qué nos ha traído y qué nos ha quitado?, es necesario que empecemos a rechazar la idea del "subdesarrollo" y revisar nuestra mirada colonizada que considera superior todo lo que viene de afuera y comencemos a dar valor a nuestros recursos naturales y humanos. Otro aspecto importante es reivindicar el derecho a vivir desde nuestra cultura. Las propuestas son varias, pero lo que más se requiere para hacer cambios profundos en el sistema nacional e internacional contemporáneo es una actitud comprometida que a ciudadanía participe de manera activa en los espacios de interés común y hacer presión para influir directamente en los foros y debates políticos de la comunidad internacional.

El discurso del desarrollo predica el crecimiento económico como solución a todas las crisis, sin embargo, en el pasado muchos países vieron crecer sus economías sin que esto implicara mejoras en la calidad de vida de sus pobladores. Ante esta realidad, en la región mujeres y hombres, se dedican a sostener y crear prácticas sociales y solidarias que se orientan al bien común. También, algunos gobiernos están creado políticas sociales que están más apegadas al contexto socioeconómico de las familias, sin embargo, muchas veces estas experiencias se mantienen contra viento y marea, y contra políticas injerencistas de países de otras regiones del mundo que tienen poder adquisitivo mayor al de los pueblos del sur.

Posiblemente por eso es que América Latina es la región donde más movimientos sociales se están formando, este despertar de la ciudadanía nos obliga a tratar de difundir la demanda popular que pide el cambio de estructura, de las formas de producción y de consumo para que estas sean justas y equitativas, donde se permita la igualdad de oportunidades para todas y todos. Expandir este sentimiento de cambio es tarea de todos los grupos sociales latinoamericanos, pues para generar transformaciones se requiere de la participación masiva de los ciudadanos.

Según la doctora Tahina Ojeda la reformulación del desarrollo implica empezar a plantearnos sobre lo que entendemos realmente por desarrollo, considero que un punto interesante para lograr esa transformación del enfoque es que las sociedades trabajen por democratizar los distintos sistemas políticos del mundo, para que en las agendas de gobierno sean incluidas las voces de los ciudadanos y así participen en la toma de decisiones, además, que el ejercicio político estatal no sea dirigido por un grupo reducido de personas que buscan favorecer sus intereses y no los de la mayoría. Democratizar la democracia implica empezar a cuestionar el actuar de los organismos 
intergubernamentales y desafiar su poderío, hoy por hoy, las decisiones sobre cómo debe orientarse el mundo es asunto solamente de algunos países imperiales, la mayoría de naciones lo único que hace es aprobar y ejecutar las acciones que las potencias mundiales dictan.

El despertar de América Latina y del mundo no desarrollado, es un reto que debe ser compartido entre las naciones marginadas. Aunque los países en vías de desarrollo no posean el control del poder económico y militar, todavía les es posible conquistar nuevos horizontes y formar la organización social que les permita a todas y todos los habitantes del planeta tener una vida digna. Comparto la idea de la doctora Ojeda en cuanto considera que la trasformación mundial puede convertirse en realidad si los gobiernos y sociedad civil empiezan a trabajar con agendas diversificadas condicionadas al contexto de cada territorio, y donde la injerencia imperial sea sofocada con nuevas alianzas entre las regiones que profesan la seguridad y la paz mundial.

Al analizar el contexto internacional y las visiones críticas actuales considero posible replantear y cuestionar las ideas acerca del desarrollo y plantear un despertar masivo de la sociedad para que se creen nuevos modelos de inclusión social y desarrollo.

Al replantear las ideas acerca del desarrollo no se trata de cerrar nuestras mentes a influencias de otras culturas u otros países, lo que se requiere es aprender desde la vida académica a educarnos y formarnos desde nuestro contexto local, cultural y según nuestras necesidades de conocimiento. Necesitamos una educación descolonizada que nos enseñe a preguntar, a pensar, a cuestionar, a inventar y a crear. Una educación que nos libere en lugar de disciplinarnos, reducirnos y encarrilarnos en un camino trazado con anterioridad.

Considero decisiva la participación de los diplomáticos de los países de América Latina y el Caribe en los organismos y organizaciones internacionales que configuran el orden mundial, pues aunque no ejercemos el control total del poder de la política mundial, la postura que adopta cada representante de la región, es fundamental para influir en las acciones que se implementarán para librar las batallas contra la pobreza, el hambre, la desigualdad y la injusticia. La solidaridad común debe ser el principio rector de las relaciones internacionales de las naciones de América Latina y el Caribe.

\section{Fuente consultada}

Ojeda, T. (2015). Ciclo de conferencias: Cooperación internacional y desarrollo: Reflexiones críticas. Madrid, España. https:/www.youtube.com/watch?list=LLcEgfK_2EwJabPHZFTkWLg\&v=5mu5XTe5PIc 